CLINICAL STUDY

\title{
The association of thyroid function with carotid artery plaque burden and strokes in a population-based sample from a previously iodine-deficient area
}

\author{
Marcus Dörr ${ }^{1}$, Klaus Empen ${ }^{1}$, Daniel M Robinson ${ }^{1}$, Henri Wallaschofski ${ }^{2}$, Stephan B Felix ${ }^{1}$ and Henry Völzke ${ }^{3}$ \\ Departments of ${ }^{1}$ Cardiology, Angiology and Pulmonology, ${ }^{2}$ Gastroenterology, Endocrinology and Nutrition and ${ }^{3}$ Institute for Community Medicine, Ernst- \\ Moritz-Arndt-University, 17475 Greifswald, Germany \\ (Correspondence should be addressed to M Dörr who is now at Department of Internal Medicine B, Ernst Moritz Arndt University, Friedrich Loeffler Str. \\ 23 a, D-17475 Greifswald, Germany; Email: mdoerr@uni-greifswald.de)
}

\begin{abstract}
Background: Thyroid dysfunction is associated with detrimental cardiovascular effects. We analyzed whether thyroid status is related to carotid artery plaques and prevalent strokes.

Design, patients and measurements: Data from 2128 subjects (1157 men and 971 women) aged $\geq 45$ years without thyroid diseases participating in the Study of Health in Pomerania were analyzed. The presence of carotid plaques was assessed by B-mode ultrasound and prevalent stroke was assessed by interview. The sample was divided according to the reference range of serum TSH levels into decreased $(<0.25 \mathrm{mIU} / \mathrm{l})$, normal $(0.25-2.12 \mathrm{mIU} / \mathrm{l})$, and elevated $(>2.12 \mathrm{mIU} / \mathrm{l})$. Logistic regression models were adjusted for common confounders including age, sex, BMI, hypertension, diabetes mellitus, smoking, school education, plasma fibrinogen and serum cholesterol levels, and statins.

Results: The prevalence of carotid plaques at any site was higher in subjects with decreased serum TSH levels (81.7\%) compared with normal serum TSH levels (70.2\%) and elevated serum TSH levels (65.6\%; $P<0.001$ ). Fully adjusted logistic regression models revealed increased odds for carotid plaques (odds ratio (OR) 1.67; 95\% confidence interval (CI) 1.11-2.51; $P<0.05)$ as well as for prevalent strokes (OR 1.98; 95\% CI 1.05-3.73; $P<0.05)$ in subjects with decreased serum TSH levels, while there was no association between elevated serum TSH levels and carotid plaques or stroke respectively.

Conclusions: Thyroid function was associated with the presence of carotid artery plaques and prevalent strokes in this population-based sample. Periodical screening and early treatment of atherosclerotic risk factors should be performed in subjects with decreased serum TSH levels.

European Journal of Endocrinology 159 145-152
\end{abstract}

\section{Introduction}

Thyroid dysfunction is associated with detrimental cardiovascular effects and decreased serum thyrotropin (TSH) levels have been associated with all-cause and circulatory mortality in elderly people from the general population (1) as well as in cardiac patients (2). To a certain extent, this may be explained by an association of very low serum TSH levels with an increased incidence of atrial fibrillation and resulting cardioembolic events (3). On the other hand, hypothyroidism is associated with an increased risk of atherosclerosis (4-7). Data concerning the role of overt and subclinical hyperthyroidism in the development of atherosclerosis are still inconclusive. Studies have suggested both proatherosclerotic effects in subjects with decreased serum TSH levels (8) and protective effects of thyroxin against atherosclerosis $(9,10)$.

Carotid artery plaque burden is a marker of generalized atherosclerosis (11-13) and increased cardiovascular and all-cause mortality risk (14-16).
Presence of atherosclerotic plaques in the internal carotid artery is associated with an increased risk of incident stroke even in asymptomatic adults aged 65 years or older (17). Thus, an association between thyroid dysfunction and carotid artery plaques might at least partly explain the elevated cardiovascular morbidity and mortality reported in thyroid dysfunction $(18,19)$.

The aim of the present study was to provide evidence for an association between thyroid function, carotid artery plaque, and prevalent stroke in a populationbased sample, supporting the hypothesis of an elevated cardiovascular risk in thyroid dysfunctions.

\section{Methods}

\section{Study population}

The Study of Health in Pomerania (SHIP) is a crosssectional study in the northeastern area of Germany. 
A sample from the population aged 20-79 years was drawn using population registries. Finally, 7008 subjects were sampled, with 292 randomly selected persons of each sex in each of the twelve 5-year age strata. The net sample (excluding migrated or deceased persons) comprised 6267 eligible subjects. The SHIP sample comprised 4310 participants $(68.8 \%$ of eligible subjects). Data were collected between October 1997 and May 2001. All participants gave informed written consent. The study was approved by the Ethics Committee of the University of Greifswald.

In the SHIP population, only participants aged $\geq 45$ years $(n=2502)$ received carotid ultrasound. Subjects without values of serum TSH levels $(n=107)$ and with known or possible thyroid diseases $(n=267)$ were excluded from analyses, resulting in a final study population of 2128 subjects available for the present analysis.

\section{Participant characteristics}

Sociodemographic and medical characteristics were assessed by computer-assisted personal interviews including the following: age, sex, school education $(<10,10$, and $>10$ years; categorization on the basis of the organization of the East German school system), pack years, and alcohol consumption (0, 1-20, 21-60, and $>60 \mathrm{~g}$ per day). Prevalent diabetes, myocardial infarction, and stroke were defined as self-reported physician's diagnoses. Study participants were classified as never smoker, ex-smoker or current smoker. They were considered physically active if they participated in physical training during summer or winter for at least $1 \mathrm{~h}$ a week. Present medication was recorded by a computer-aided method using the anatomic, therapeutic, and chemical code. Systolic and diastolic blood pressure was measured three times in seated subjects after a 5-min rest period, with each reading being followed by a further rest period of 3 min. Mean blood pressure was calculated from the last two measurements. Pulse pressure was defined as the difference between mean systolic and diastolic measurements. Height and weight were measured for the calculation of body mass index $\left(\mathrm{BMI}=\right.$ weight $(\mathrm{kg}) /$ height $\left.^{2}\left(\mathrm{~m}^{2}\right)\right)$.

\section{Laboratory parameters}

Serum TSH was analyzed by immunochemiluminescent procedures (LIA-mat, Byk Sangtec Diagnostica GmbH, Frankfurt, Germany). The functional sensitivity of the TSH assay was $0.03 \mathrm{mIU} / \mathrm{l}$. Serum autoantibodies to thyroperoxidase (TPOAb) were measured by an enzyme immunoassay (VARELISA, Elias Medizintechnik GmbH, Freiburg, Germany). The functional sensitivity of this assay was $1 \mathrm{IU} / \mathrm{ml}$. The reference range was $<60 \mathrm{IU} / \mathrm{ml}$ for men and $<100 \mathrm{IU} / \mathrm{ml}$ for women. The TPOAb status was defined as positive if values exceeded $200 \mathrm{IU} / \mathrm{ml}$ (20). Enzymatic methods were used to measure total serum cholesterol (CHOD-PAP reagent, Boehringer $\mathrm{GmbH}$, Mannheim, Germany) (21). Serum low-density and high-density lipoprotein cholesterol were precipitated and measured photometrically (Boehringer $\mathrm{GmbH}$, Mannheim, Germany). Plasma fibrinogen concentrations were assayed according to Clauss (22), using an Electra 1600 analyzer (Instrumentation Laboratory, Barcelona, Spain). Serum hemoglobin $\mathrm{Hb}) \mathrm{A} 1 \mathrm{C}$ was determined by high performance thinlayer chromatography (Bio-Rad Diamat), and lipoprotein (a) concentrations were determined with use of an immunoluminometric assay (Magic Lite Analyzer II Ciba Corning, MA, USA).

\section{Ultrasound measurements}

Certified medical assistants examined the thyroid and extracranial carotid arteries bilaterally with B-mode ultrasound using a $5 \mathrm{MHz}$ linear array transducer and a high-resolution instrument (Diasonics VST Gateway, Santa Clara, CA, USA). Both the near and far walls of the common carotid, the internal carotid, the external carotid, and the carotid bifurcations on both sides were evaluated online for the presence of atherosclerotic plaques. Each vessel segment was visualized in multiple longitudinal and transversal planes. Atherosclerotic plaques were defined by the following criteria (23): a) focal thickening relative to adjacent segments (as evidenced by protrusion into the lumen and/or localized roughness with increased echogenicity) and b) an area of focal increased thickness $(>1.3 \mathrm{~mm})$ of the intimamedia layer (23). A thyroid homogeneous echo pattern with reduced echogenicity was defined as hypoechogenic. An autoimmune thyroiditis was assumed if a hypoechogenic echo pattern of both thyroid lobes was combined with TPOAb positivity (20).

\section{Statistical analyses}

Data on quantitative characteristics are expressed as median and 25 th and 75 th percentile as indicated. Data on qualitative characteristics are expressed as percent values or absolute numbers as indicated. For analysis, the sample was divided according to the serum TSH reference range that has been recently established for the study region (24) into decreased $(<0.25 \mathrm{mIU} / \mathrm{l})$, normal $(0.25-2.12 \mathrm{mIU} / \mathrm{l})$, and elevated $(>2.12 \mathrm{mIU} / \mathrm{l})$. Comparisons among groups were made using $\chi^{2}$ test (nominal data) or Mann-Whitney U-test (interval data). Multivariable analyses were performed with logistic regression using carotid plaque or stroke as the dependent variable. The adjusted odds ratio (OR) with its $95 \%$ confidence interval (CI) was calculated. Firstly, a basic set of variables (age, sex, BMI, hypertension, diabetes mellitus, smoking status, and school education) was included in the model. Secondly, all other potential confounders were entered stepwise (criteria for entering $P=0.15$, criteria for removing $P=0.20$ ). Only variables 
that lead to a $\geq 5 \%$ change in the coefficient of interest were included in the full model, which was finally controlled for plasma fibrinogen and serum low-density lipoprotein cholesterol levels, and use of statins in addition to the basic set of variables. For all tests, a value of $P<0.05$ was considered statistically significant. Analyses were performed with SPSS software version 14.0.1 (SPSS Inc., Chicago, IL, USA).

\section{Results}

Among the 2128 subjects (1157 men and 971 women) included in the analyses, 226 had decreased (10.6\%), 1839 normal $(86.4 \%)$, and $63(3.0 \%)$ elevated serum
TSH levels. Further baseline characteristics are presented in Table 1. Compared with those with normal serum TSH levels, subjects with decreased serum TSH levels were older. Participants with elevated serum TSH levels were more physically active, had a higher frequency of autoimmune thyroiditis, and a higher BMI in comparison with those with normal TSH levels (Table 1).

Compared with the normal TSH group, subjects with decreased serum TSH levels had a higher prevalence of carotid plaques at any location as well as higher crude frequencies of prevalent stroke (Table 2).

Inclusion of all potential confounders with the exception of the TSH status into multivariable logistic regression models revealed the following variables as independent risk factors for carotid artery sclerosis:

Table 1 Characteristics of participants with respect to serum TSH levels.

\begin{tabular}{|c|c|c|c|}
\hline Characteristics & $\begin{array}{l}\text { Decreased TSH } \\
(\mathrm{TSH}<0.25 \mathrm{mIU} / \mathrm{l})(n=226)\end{array}$ & $\begin{array}{l}\text { Normal TSH } \\
(\text { TSH } 0.25-2.12 \mathrm{mIU} / \mathrm{l})(n=1839)\end{array}$ & $\begin{array}{l}\text { Elevated TSH } \\
(\mathrm{TSH}>2.12 \mathrm{mIU} / \mathrm{l})(n=63)\end{array}$ \\
\hline Age (years) & $64.0(57.0 ; 72.0)^{\star}$ & $61.0(54.0 ; 69.0)$ & $60.0(54.0 ; 69.0)$ \\
\hline Sex (male) & $129(57.1)$ & $1010(53.0)$ & $18(28.6)$ \\
\hline \multicolumn{4}{|l|}{ School education } \\
\hline$<10$ years & $147(65.0)$ & $1091(59.4)$ & $34(54.0)$ \\
\hline 10 years & $62(27.4)$ & $512(27.9)$ & $16(25.4)$ \\
\hline$>10$ years & $17(7.5)$ & 234 (12.7) & $13(20.6)$ \\
\hline \multicolumn{4}{|l|}{ Smoking status } \\
\hline Never-smoker & 74 (32.7) & $736(40.0)$ & $26(41.3)$ \\
\hline Ex-smoker & $102(45.1)$ & 750 (40.8) & $24(38.1)$ \\
\hline Current smokers & $5000(22.1)$ & $353(19.2)$ & $13(20.6)$ \\
\hline Pack years & $20.0(13.6 ; 31.1)$ & $26.0(14.9 ; 34.0)$ & $26.5(11.8 ; 43.3)$ \\
\hline \multicolumn{4}{|l|}{ Alcohol consumption per day } \\
\hline $0 \mathrm{~g}$ & $103(45.6)$ & $653(35.5)$ & $24(38.1)$ \\
\hline $1-20 \mathrm{~g}$ & $66(29.2)$ & $619(33.7)$ & $26(41.4)$ \\
\hline $21-60 \mathrm{~g}$ & $49(21.7)$ & 457 (24.9) & $12(19.0)$ \\
\hline$>60 \mathrm{~g}$ & $8(3.5)$ & $109(5.9)$ & $1(1.6)$ \\
\hline Physically active & $79(35.0)$ & $621(33.8)$ & $29(46.0)^{*}$ \\
\hline Diabetes mellitus & $15(11.1)$ & $230(12.5)$ & $4(6.3)$ \\
\hline Hypertension & $150(66.4)$ & $1275(69.3)$ & $35(55.6)$ \\
\hline Myocardial infarction & $14(6.3)$ & $102(5.6)$ & $3(4.8)$ \\
\hline Autoimmune thyroiditis & $1(0.4)$ & $13(0.7)$ & $14(22.2)^{\star}$ \\
\hline Body mass index $\left(\mathrm{kg} / \mathrm{m}^{2}\right)$ & $27.8(25.4 ; 30.4)$ & $28.0(25.3 ; 30.9)$ & $29.7(26.3 ; 33.7)^{\star}$ \\
\hline \multicolumn{4}{|l|}{ Blood pressure } \\
\hline Systolic (mmHg) & $142(129 ; 156)$ & $143(130 ; 157)$ & $136(126 ; 155)$ \\
\hline Diastolic $(\mathrm{mmHg})$ & $85(77 ; 92)$ & $85(79 ; 93)$ & $85(79 ; 93)$ \\
\hline Heart rate (beats per min) & $72.0(65.0 ; 79.5)$ & $71.5(64.0 ; 79.5)$ & $69.5(63.0 ; 75.0)$ \\
\hline \multicolumn{4}{|l|}{ Medication } \\
\hline ACE inhibitors & $49(21.7)$ & $383(20.8)$ & $14(22.2)$ \\
\hline AT-II antagonists & $6(2.7)$ & $62(3.4)$ & $3(4.8)$ \\
\hline Calcium-channel blockers & $42(18.6)$ & $336(18.3)$ & $8(12.7)$ \\
\hline Statins & $28(12.4)$ & $178(9.7)$ & $2(3.2)$ \\
\hline Salicylic acid & $22(9.7)$ & $220(12.0)$ & $8(12.7)$ \\
\hline \multicolumn{4}{|l|}{ Laboratory parameters } \\
\hline TSH (mÚ/l) & $0.2(0.1 ; 0.2)^{\star}$ & $0.6(0.5 ; 0.9)$ & $2.9(2.4 ; 5.1)^{\star}$ \\
\hline TPOAb (IU/ml) & $0.5(0.5 ; 4.1)$ & $1.1(0.5 ; 5.2)$ & $86.3(0.9 ; 533.4)^{\star}$ \\
\hline Fibrinogen $(\mathrm{g} / \mathrm{l})$ & $3.2(2.7 ; 3.7)^{\star}$ & $3.0(2.6 ; 3.5)$ & $3.0(2.6 ; 3.7)$ \\
\hline Cholesterol (mmol/l) & $5.6(5.1 ; 6.4)^{*}$ & $6.0(5.3 ; 6.8)$ & $6.5(5.5 ; 7.4)^{*}$ \\
\hline LDL-C (mmol/l) & $3.6(2.9 ; 4.1)^{*}$ & $3.8(3.1 ; 4.5)$ & $4.2(3.1 ; 5.0)^{\star}$ \\
\hline $\mathrm{HDL}-\mathrm{C}(\mathrm{mmol} / \mathrm{l})$ & $1.3(1.1 ; 1.6)$ & $1.4(1.1 ; 1.7)$ & $1.5(1.2 ; 1.7)^{\star}$ \\
\hline Lipoprotein (a) (mg/l) & $115(56 ; 283)$ & $97(43 ; 273)$ & $103(45 ; 367)$ \\
\hline $\mathrm{HbA1c}(\%)$ & $5.5(5.2 ; 6.0)$ & $5.5(5.1 ; 6.0)$ & $5.4(5.1 ; 6.0)$ \\
\hline
\end{tabular}

Continuous data are given as median (25th; 75th percentile); nominal data are given as absolute numbers (percentage values). TSH, serum thyrotropin; TPOAb, serum autoantibodies to thyroperoxidase; LDL-C, serum low-density lipoprotein cholesterol; HDL-C, high-density lipoprotein cholesterol; HbA1c, serum hemoglobin A1C. * $P<0.05 ; \chi^{2}$-test (nominal data) or Mann-Whitney $U$-test (interval data); comparisons were performed separately against the group with normal serum TSH levels. 
Table 2 Carotid artery characteristics and prevalent stroke by TSH groups.

\begin{tabular}{lllll}
\hline Characteristics & $\begin{array}{l}\text { Decreased TSH } \\
(\mathrm{TSH}<0.25 \mathrm{mIU} / \mathrm{l})(n=226)\end{array}$ & $\begin{array}{l}\text { Normal TSH } \\
(\mathrm{TSH} 0.25-2.12 \mathrm{mIU} / \mathrm{l})(n=1839)\end{array}$ & $\begin{array}{l}\text { Elevated TSH } \\
(\mathrm{TSH}>2.12 \mathrm{mlU} / \mathrm{l})(n=63)\end{array}$ \\
\hline Carotid plaque & & & & $\boldsymbol{P}^{\mathrm{a}}$ \\
Common carotid artery & $31(13.7)$ & $216(11.8)$ & $2(3.2)$ & 0.07 \\
Bifurcation & $168(74.3)$ & $1148(62.5)$ & $31(49.2)$ & $<0.001$ \\
Internal carotid artery & $98(44.5)$ & $686(38.2)$ & $18(31.0)$ & 0.09 \\
External carotid artery & $64(29.2)$ & $475(26.6)$ & $47(28.3)$ & 0.68 \\
Any location & $183(81.7)$ & $1278(70.2)$ & $40(65.6)$ & $<0.001$ \\
Stroke & $16(7.1)$ & $67(3.7)$ & $2(3.2)$ & 0.04 \\
\hline
\end{tabular}

Data are given as absolute numbers (percentage values). TSH, serum thyrotropin.

${ }^{\mathrm{a}} \chi^{2}$-test.

age, higher BMI, history of hypertension or diabetes mellitus, current smoking, school education $<10$ years, high plasma fibrinogen levels, and use of statins (Table 3).

The crude as well as the adjusted statistical logistic regression models demonstrated an elevated OR for the presence of carotid artery plaques at any location for subjects with decreased serum TSH levels (OR 1.67; 95\% CI 1.11-2.51; $P<0.05$; full model) compared with those with normal serum TSH levels (Fig. 1). In addition, they had higher odds for prevalent stroke (OR 1.98; $95 \%$ CI 1.05-3.73; $P<0.05$; full model; Fig. 2). In contrast, there was no association between elevated serum TSH levels and carotid artery plaques at any location (Fig. 1) or prevalent stroke (Fig. 2) respectively.

Table 3 Risk factors for carotid artery plaque ${ }^{a}$.

\begin{tabular}{|c|c|c|}
\hline & OR $(95 \% \mathrm{Cl})$ & $P^{a}$ \\
\hline Age (year) & $1.12(1.10-1.14)$ & $<0.001$ \\
\hline Sex (reference:female) & $1.31(1.00-1.72)$ & 0.053 \\
\hline Body mass index $\left(\mathrm{kg} / \mathrm{m}^{2}\right)$ & $1.03(1.01-1.06)$ & 0.020 \\
\hline Hypertension (y/n) & $1.60(1.24-2.06)$ & $<0.001$ \\
\hline Diabetes mellitus $(y / n)$ & $1.59(1.03-2.45)$ & 0.036 \\
\hline \multicolumn{2}{|c|}{ Smoking status (reference: never-smoker) } & 0.018 \\
\hline Ex-smoker & $1.05(0.79-1.39)$ & 0.755 \\
\hline Current smokers & $1.56(1.13-2.16)$ & 0.008 \\
\hline \multicolumn{2}{|l|}{ School education (reference: $<10$ years) } & 0.018 \\
\hline 10 years & $0.75(0.58-0.98)$ & 0.037 \\
\hline$>10$ years & $0.64(0.46-0.90)$ & 0.011 \\
\hline \multicolumn{2}{|c|}{ Alcohol consumption per day (reference: $0 \mathrm{~g}$ ) } & 0.197 \\
\hline $1-20 \mathrm{~g}$ & $0.92(0.70-1.21)$ & 0.563 \\
\hline $21-60 \mathrm{~g}$ & $1.19(0.86-1.65)$ & 0.290 \\
\hline$>60 \mathrm{~g}$ & $1.52(0.90-2.56)$ & 0.117 \\
\hline Physical active (y/n) & $0.92(0.72-1.16)$ & 0.475 \\
\hline thyroiditis $(y / n)$ & $1.66(0.62-4.44)$ & 0.314 \\
\hline Fibrinos & $1.20(1.00-1.44)$ & 0.049 \\
\hline LDL-C (mmol/l) & $1.11(1.00-1.22)$ & 0.051 \\
\hline Lipoprotein (a) (100 mg/l) & $1.02(0.98-1.06)$ & 0.352 \\
\hline ACE inhibitors or AT-II antagonists $(\mathrm{y} / \mathrm{n})$ & $1.06(0.76-1.48)$ & 0.745 \\
\hline -channel blockers $(y / n)$ & $1.08(0.74-1.56)$ & 0.696 \\
\hline Statir & $2.37(1.38-4.06)$ & 0.002 \\
\hline Salicylic acid (y/n) & $1.09(0.71-1.69)$ & 0.693 \\
\hline
\end{tabular}

Among the whole study population, $94(4.4 \%)$ subjects were TPOAb positive. With respect to thyroid function, TPOAb-positivity was present in 8 (3.5\%), 63 (3.4\%), and $23(36.5 \%)$ participants with low, normal, and elevated serum TSH levels respectively $(P<0.001)$. TPOAb positivity was not associated with increased odds for carotid artery plaques within the fully adjusted model (OR 1.25; 95\% CI 0.73-2.17; $P=0.42$ ) among the whole study population. Likewise, the presence of a positive TPOAb status was not related to an increased odds ratio for carotid artery plaques in subjects with low (OR 1.05; 95\% CI 0.10-11.57; $P=0.96$ ), normal (OR 1.32; 95\% CI $0.68-2.55 ; P=0.68$ ), or elevated (OR $1.68 ; 95 \%$ CI $0.09-32.87 ; P=0.73)$.

\section{Sensitivity analyses}

Since the serum TSH reference range within our study region is relatively low compared with other studies

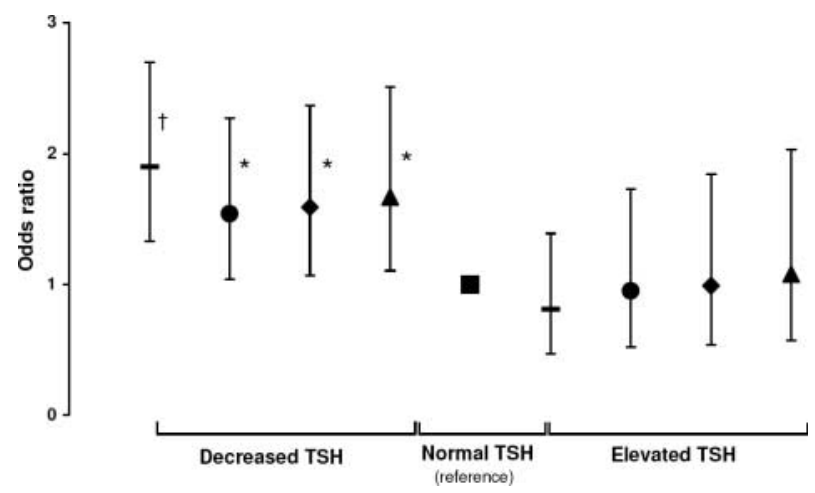

Figure 1 Association of thyroid function and carotid artery plaque. Values are odds ratio and $95 \%$ confidence intervals by serum TSH levels (logistic regression analysis), dependent variable: carotid artery plaques at any location $(\mathrm{y} / \mathrm{n}) ;{ }^{\star} P<0.05$ and ${ }^{\dagger} P<0.001$ ( $\mathbf{\square}$, reference: normal TSH); $R^{2}$ (Nagelkerke) $=0.337$ for full model. - , crude model; $\bullet$, adjusted for age and sex; - , basic set: adjusted for age, sex, BMI, hypertension, diabetes mellitus, smoking status, and school education; $\boldsymbol{\Lambda}$, full model: adjusted for plasma fibrinogen and serum low-density lipoprotein cholesterol, and use of statins in addition to the variables of the basic set. 


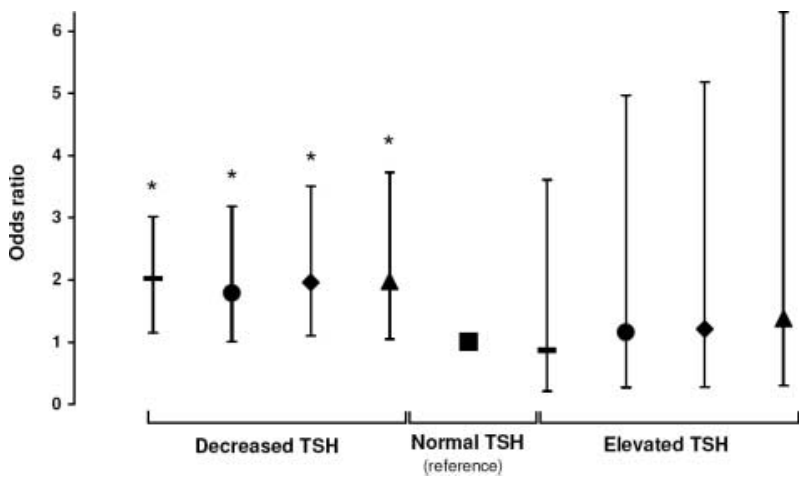

Figure 2 Thyroid function and prevalent stroke. Values are odds ratio and $95 \%$ confidence intervals by serum TSH levels (logistic regression analysis), dependent variable: history of stroke $(\mathrm{y} / \mathrm{n})$; ${ }^{*} P<0.05$ ( $\boldsymbol{\square}$, reference: normal TSH); $R^{2}$ (Nagelkerke) $=0.209$ for full model. - , crude model; $\bullet$, adjusted for age and sex; $\checkmark$, basic set: adjusted for age, sex, BMI, hypertension, diabetes mellitus, smoking status, and school education; $\boldsymbol{\Delta}$, full model: adjusted for plasma fibrinogen and serum low-density lipoprotein cholesterol, and use of statins in addition to the variables of the basic set.

(24), we performed some additional sensitivity analyses using varying cut-offs. These analyses did not substantially change the main results. For example, when the lower limit of TSH was defined $<0.4 \mathrm{mIU} / \mathrm{l}$ and the upper limit $>4.0 \mathrm{mIU} / \mathrm{l}, 566(26.6 \%)$ subjects had decreased, 1539 (72.3\%) normal, and 23 (1.1\%) elevated serum TSH levels. The OR for carotid plaque (full model) was then 1.32 (95\% CI 1.01-1.73; $P=0.039)$ in subjects with decreased serum TSH levels compared with those with normal serum TSH levels, while it was not statistically significant among those with elevated serum TSH levels (OR 0.52; 95\% CI 0.191.45; $P=0.212$ ). With respect to logistic regression models for strokes, further analyses were performed including plaque variables in addition to the full statistical model in order to test for possible modulations. However, this did not have any substantial effects on the above reported findings. For example, the OR for stroke was 1.95 (95\% CI 1.03-3.69) for subjects with decreased serum TSH levels after inclusion of the variable plaque at any location in the full model.

\section{Discussion}

The present study revealed an association between thyroid function, carotid plaques, and stroke prevalence. Subjects with decreased serum TSH levels had increased odds for the presence of carotid plaques compared with those with normal serum TSH levels. This relationship remained statistically significant after appropriate adjustment for major atherosclerotic risk factors. The occurrence of carotid plaques is associated with generalized atherosclerosis (11-13). Besides thyroid function, we also identified traditional cardiovascular risk factors as independent predictors for carotid plaques. This emphasizes the validity of our methods to determinate carotid plaques.

Our results showing an increased OR for carotid plaques in subjects with decreased serum TSH levels supplement recent analyses from SHIP (8) that have demonstrated higher values of the intima-media thickness (IMT) of the common carotid artery in subjects with decreased serum TSH levels compared with euthyroid subjects. Increased IMT of the common carotid artery has been shown to be a valid marker of both coronary (25), and generalized atherosclerosis $(13,26)$, as well as a predictor of future cardiovascular events (27). Our observation is further strengthened by the data on stroke prevalence that was also higher in subjects with decreased serum TSH compared with those with normal levels. This association was very strong, although the prevalence of stroke in our population was relatively low. Only few previous studies have investigated a possible linkage between thyroid function and stroke. In contrast to our findings, data from a 20-year follow-up of 5269 participants aged 25-74 years at baseline of the First National Health and Nutrition Examination Survey demonstrated a significantly higher relative risk for all strokes (relative risk 1.6; 95\% CI 1.0-2.6) and ischemic stroke (relative risk 1.6; 95\% CI 1.0-2.7) respectively, in hypothyroid subjects (28). These discrepancies might be explained at least in part by differences concerning the study design and the study populations. In the latter study (28), analyses were performed only with respect to a possible relation between (overt) hyperthyroidism and stroke, but not with a focus on decreased serum TSH levels or subclinical hyperthyroidism. Our study region is an area of former iodine deficiency (29) where decreased serum TSH values are more common (20, 24, $30,31)$ when compared with the National Health and Nutrition Examination Survey (28). Moreover, hyperthyroidism after iodine supplementation predominantly affects older people (32). Accordingly, the mean age of subjects with low TSH levels among our study sample was significantly higher than in the two other groups. Thus, it cannot be excluded that the observed relation between low serum TSH levels and increased stroke prevalence might be of particular importance in iodine deficiency areas. Another recent retrospective study in 744 consecutive acute stroke patients, however, has demonstrated a better clinical outcome in patients with a pre-existing hypothyroid function (33). Partly in line with these findings, subjects with elevated serum TSH levels in our study had a decreased OR for prevalent stroke as well, although this was far from statistical significance.

Our findings of an association between decreased serum TSH levels, carotid plaque, and stroke might point towards an increased atherosclerostic risk in affected persons. These results seemingly support the hypothesis of an increased all-cause and circulatory 
mortality in elderly subjects from the general population with low serum TSH levels (1). Recently, an increased risk of cardiac death has also been demonstrated for subclinical hyperthyroidism, low tri-iodothyronine $\left(\mathrm{T}_{3}\right)$ syndrome, and subclinical hypothyroidism compared with euthyroidism during a 32-month follow-up in cardiac patients (2). In contrast to our study, these were patients with pre-existing cardiovascular diseases and not relatively healthy subjects from the general population, thus representing a completely different population.

The biological mechanisms that could link low serum TSH levels with atherosclerosis within our study population remain to be elucidated. Thus, our findings are in conflict with some studies that have demonstrated an association between hypothyroidism and an elevated risk for atherosclerosis (4-7). Elevation of serum lipids is probably a major factor for this association (34). In addition, some studies have demonstrated an association between thyroid autoimmunity and coronary heart disease in (subclinical) hypothyroidism (35-37), while we did not find any association between TPO antibody positivity itself, carotid plaque formation and serum TSH levels in any direction. For low TSH values, this is in line with a previous study that could not confirm an association between thyroid antibodies and atherosclerosis in hypothyroid subjects $(5,38,39)$. Regarding the association of low serum TSH levels, carotid plaque formation, and prevalent stroke, the interpretation is much more complex. At first glance, our results seem to be in contrast to other data that showed even protective effects against atherosclerosis $(9,10)$, an improvement in endothelial-dependent vasodilation by $\mathrm{T}_{3}$ therapy (40) or an increased NO availability in hyperthyroid patients (41). On the other hand, it has been demonstrated that overt hyperthyroidism may cause systolic hypertension by positive inotropic and chronotropic effects of thyroid hormones $(42,43)$. Another study found a small decline of mean daytime systolic blood pressure in ten younger subjects with subclinical hyperthyroidism after restoration of euthyroidism by radioiodine or antithyroid treatment (44). Hypertension is not only an important risk factor for the development of atherosclerosis, but also may contribute to increased vascular stiffness, which is a marker of subclinical atherosclerosis (45). In fact, two studies have reported increased vascular stiffness of carotid arteries in patients with hyperthyroid Graves' disease $(46,47)$. Thus, such associations could hypothetically explain in part the relation of low serum TSH levels and carotid plaque formation observed in our study. However, due to the cross-sectional design, we are not able to draw any causal conclusions with respect to thyroid function and carotid plaque formation or stroke prevalence.

Some further limitations need to be considered for the interpretation of our data. Our results are derived from a general population living in a former iodine deficiency area (29). Thus, extrapolation to patient collectives and other population is not generally possible. Furthermore, patients with atherosclerotic diseases, including strokes, may have received iodine containing contrast agents that may have potentially influenced serum TSH levels (48), and misclassification bias in the exposure definition might have affected the results. Moreover, it cannot completely be excluded that in some subjects thyroid function was altered due to a non-thyroidal illness. However, since data are taken from a population-based study, the possibility of coexisting severe diseases was very low. Although we carefully controlled our analyses for imbalances in confounding factors including age, sex, and cardiovascular risk factors among the exposure groups, we cannot fully rule out residual confounding by some of these factors. The large sample size, the availability of data on key risk factors, the wide range of age of participants, and the consistence of our findings over a number of sensitivity analyses are strengths of our study. Additional studies are needed to confirm the demonstrated associations focusing particularly on subjects with subclinical thyroid dysfunctions. Follow-up investigations are required to investigate the prognostic value of the relationship between thyroid function, carotid plaques, and stroke as a strong and independent predictor of all-cause and cardiovascular mortality (14-16).

In conclusion, we demonstrated an association between thyroid function, carotid artery plaque burden, and prevalent stroke among the normal population. Since this may reflect an increased atherosclerotic state in subjects with decreased serum TSH levels, they should be periodically screened for atherosclerotic diseases, and concomitant risk factors should be treated at an early stage.

\section{Acknowledgements}

This work is part of the Community Medicine Research net (CMR) of the University of Greifswald, Germany, which is funded by the Federal Ministry of Education and Research (grant no. ZZ9603), the Ministry of Cultural Affairs as well as the Social Ministry of the Federal State of Mecklenburg-West Pomerania. The CMR encompasses several research projects that share data from the population-based Study of Health in Pomerania (SHIP; http://www.medizin.uni-greifswald. $\mathrm{de} / \mathrm{cm})$. The contribution to data collection made by field workers, technicians, interviewers, and computer assistants is gratefully acknowledged. This project was further supported by the German Research Foundation (DFG Vo 955/5-1).

\section{References}

1 Parle J, Maisonneuve P, Sheppard M, Boyle P \& Franklyn J. Prediction of all-cause and cardiovascular mortality in elderly people from one low serum thyrotropin result: a 10-year cohort study. Lancet 2001358 861-865. 
2 Iervasi G, Molinaro S, Landi P, Taddei MC, Galli E, Mariani F, L'Abbate A \& Pingitore A. Association between increased mortality and mild thyroid dysfunction in cardiac patients. Archives of Internal Medicine $2007 \mathbf{1 6 7} 1526-1532$.

3 Sawin CT, Geller A, Wolf PA, Belanger AJ, Baker E, Bacharach P, Wilson PW, Benjamin EJ \& D'Agostino RB. Low serum thyrotropin concentrations as a risk factor for atrial fibrillation in older persons. New England Journal of Medicine 1994331 1249-1252.

4 Vanhaelst L, Neve P, Chailly P \& Bastenie PA. Coronary-artery disease in hypothyroidism. Observations in clinical myxoedema. Lancet 19672 800-802.

5 Hak AE, Pols HA, Visser TJ, Drexhage HA, Hofman A \& Witteman JC. Subclinical hypothyroidism is an independent risk factor for atherosclerosis and myocardial infarction in elderly women: the Rotterdam Study. Annals of Internal Medicine 2000 132 270-278.

6 Biondi B \& Klein I. Hypothyroidism as a risk factor for cardiovascular disease. Endocrine 2004 24 1-13.

7 Rodondi N, Aujesky D, Vittinghoff E, Cornuz J \& Bauer DC. Subclinical hypothyroidism and the risk of coronary heart disease: a meta-analysis. American Journal of Medicine 2006119 541-551.

8 Völzke H, Robinson DM, Schminke U, Ludemann J, Rettig R, Felix SB, Kessler C, John U \& Meng W. Thyroid function and carotid wall thickness. Journal of Clinical Endocrinology and Metabolism $2004892145-2149$.

9 Perk M \& O'Neill BJ. The effect of thyroid hormone therapy on angiographic coronary artery disease progression. Canadian Journal of Cardiology 199713 273-276.

10 Monzani F, Caraccio N, Kozakowa M, Dardano A, Vittone F, Virdis A, Taddei S, Palombo C \& Ferrannini E. Effect of levothyroxine replacement on lipid profile and intima-media thickness in subclinical hypothyroidism: a double-blind, placebo-controlled study. Journal of Clinical Endocrinology and Metabolism 200489 2099-2106.

11 Held C, Hjemdahl P, Eriksson SV, Bjorkander I, Forslund L \& Rehnqvist N. Prognostic implications of intima-media thickness and plaques in the carotid and femoral arteries in patients with stable angina pectoris. European Heart Journal 200122 62-72.

12 Touze E, Warlow CP \& Rothwell PM. Risk of coronary and other nonstroke vascular death in relation to the presence and extent of atherosclerotic disease at the carotid bifurcation. Stroke 200637 2904-2909.

13 Rohani M, Jogestrand T, Ekberg M, van der Linden J, Kallner G, Jussila $\mathrm{R} \&$ Agewall $\mathrm{S}$. Interrelation between the extent of atherosclerosis in the thoracic aorta, carotid intima-media thickness and the extent of coronary artery disease. Atherosclerosis $2005179311-316$

14 Stork S, van den Beld AW, von Schacky C, Angermann CE, Lamberts SW, Grobbee DE \& Bots ML. Carotid artery plaque burden, stiffness, and mortality risk in elderly men: a prospective, population-based cohort study. Circulation 2004 $110344-348$

15 Blacher J, Guerin AP, Pannier B, Marchais SJ \& London GM. Arterial calcifications, arterial stiffness, and cardiovascular risk in end-stage renal disease. Hypertension 200138 938-942.

16 Spence JD, Eliasziw M, DiCicco M, Hackam DG, Galil R \& Lohmann T. Carotid plaque area: a tool for targeting and evaluating vascular preventive therapy. Stroke 200233 2916-2922.

17 Polak JF, Shemanski L, O'Leary DH, Lefkowitz D, Price TR, Savage PJ, Brant WE \& Reid C. Hypoechoic plaque at US of the carotid artery: an independent risk factor for incident stroke in adults aged 65 years or older. Cardiovascular Health Study. Radiology $1998 \mathbf{2 0 8}$ 649-654.

18 Gussekloo J, van Exel E, de Craen AJ, Meinders AE, Frolich M \& Westendorp RG. Thyroid status, disability and cognitive function, and survival in old age. Journal of the American Medical Association $20042922591-2599$.

19 Imaizumi M, Akahoshi M, Ichimaru S, Nakashima E, Hida A, Soda M, Usa T, Ashizawa K, Yokoyama N, Maeda R, Nagataki S \&
Eguchi K. Risk for ischemic heart disease and all-cause mortality in subclinical hypothyroidism. Journal of Clinical Endocrinology and Metabolism 200489 3365-3370.

20 Völzke H, Ludemann J, Robinson DM, Spieker KW, Schwahn C, Kramer A, John U \& Meng W. The prevalence of undiagnosed thyroid disorders in a previously iodine-deficient area. Thyroid $200313803-810$.

21 Siedel J, Hagele E, Ziegenhorn J \& Wahlefeld A. Reagent for the enzymatic determination of serum total cholesterol with improved lipolytic efficiency. Clinical Chemistry 198329 1075-1080.

22 Clauss A. Gerinnungsphysiologische Schnellmethode zur Bestimmung des Fibrinogens. Acta Haematologica 195717 237-246.

23 Wolff B, Volzke H, Ludemann J, Robinson D, Vogelgesang D, Staudt A, Kessler C, Dahm JB, John U \& Felix SB. Association between high serum ferritin levels and carotid atherosclerosis in the study of health in Pomerania (SHIP). Stroke 200435 453-457.

24 Völzke H, Alte D, Kohlmann T, Ludemann J, Nauck M, John U \& Meng W. Reference intervals of serum thyroid function tests in a previously iodine-deficient area. Thyroid 200515 279-285.

25 Chambless LE, Heiss G, Folsom AR, Rosamond W, Szklo M, Sharrett AR \& Clegg LX. Association of coronary heart disease incidence with carotid arterial wall thickness and major risk factors: the Atherosclerosis Risk in Communities (ARIC) Study, 1987-1993. American Journal of Epidemiology $1997 \mathbf{1 4 6}$ 483-494.

26 Kablak-Ziembicka A, Przewlocki T, Tracz W, Pieniazek P, Musialek P, Stopa I, Zalewski J \& Zmudka K. Diagnostic value of carotid intima-media thickness in indicating multi-level atherosclerosis. Atherosclerosis 2007193 395-400.

27 Lorenz M, Markus H, Bots M, Rosvall M \& Sitzer M. Prediction of clinical cardiovascular events with carotid intima-media thickness. A systematic review and meta-analysis. Circulation 2007 115 459-467.

28 Qureshi AI, Suri FK, Nasar A, Kirmani JF, Divani AA \& Giles WH. Free thyroxine index and risk of stroke: results from the National Health and Nutrition Examination Survey Follow-up Study. Medical Science Monitor 200612 CR501-CR506.

29 Meng W \& Schindler A. Iodine supply in Germany, WHO/EURO/NUT $19989821-27$.

30 Teng W, Shan Z, Teng X, Guan H, Li Y, Teng D, Jin Y, Yu X, Fan C, Chong W, Yang F, Dai H, Yu Y, Li J, Chen Y, Zhao D, Shi X, Hu F, Mao J, Gu X, Yang R, Tong Y, Wang W, Gao T \& Li C. Effect of iodine intake on thyroid diseases in China. New England Journal of Medicine $20063542783-2793$.

31 Laurberg P, Pedersen KM, Hreidarsson A, Sigfusson N, Iversen E \& Knudsen PR. Iodine intake and the pattern of thyroid disorders: a comparative epidemiological study of thyroid abnormalities in the elderly in Iceland and in Jutland, Denmark. Journal of Clinical Endocrinology and Metabolism 199883 765-769.

32 Delange F \& Lecomte P. Iodine supplementation: benefits outweigh risks. Drug Safety 200022 89-95.

33 Alevizaki M, Synetou M, Xynos K, Alevizaki CC \& Vemmos KN. Hypothyroidism as a protective factor in acute stroke patients. Clinical Endocrinology $2006 \mathbf{6 5} 369-372$.

34 Canaris GJ, Manowitz NR, Mayor G \& Ridgway EC. The Colorado thyroid disease prevalence study. Archives of Internal Medicine 2000 $160526-534$.

35 Dean JW \& Fowler PB. Exaggerated responsiveness to thyrotrophin releasing hormone: a risk factor in women with coronary artery disease. BMJ 1985290 1555-1561.

36 Tieche M, Lupi GA, Gutzwiller F, Grob PJ, Studer H \& Burgi H. Borderline low thyroid function and thyroid autoimmunity. Risk factors for coronary heart disease? British Heart Journal 198146 202-206.

37 Bastenie PA, Vanhaelst L, Golstein J \& Smets P. Asymptomatic autoimmune thyroiditis and coronary heart-disease. Crosssectional and prospective studies. Lancet 19772 155-158.

38 Vanderpump MP, Tunbridge WM, French JM, Appleton D, Bates D, Clark F, Grimley Evans J, Rodgers H, Tunbridge F \& Young ET. The 
development of ischemic heart disease in relation to autoimmune thyroid disease in a 20-year follow-up study of an English community. Thyroid 19966 155-160.

39 Miura S, Iitaka M, Suzuki S, Fukasawa N, Kitahama S, Kawakami Y, Sakatsume Y, Yamanaka K, Kawasaki S, Kinoshita S, Katayama S, Shibosawa T \& Ishii J. Decrease in serum levels of thyroid hormone in patients with coronary heart disease. Endocrine Journal 199643 657-663.

40 Napoli R, Guardasole V, Angelini V, Zarra E, Terracciano D, D’Anna C, Matarazzo M, Oliviero U, Macchia V \& Sacca L. Acute effects of triiodothyronine on endothelial function in human subjects. Journal of Clinical Endocrinology and Metabolism 200792 250-254.

41 Napoli R, Biondi B, Guardasole V, Matarazzo M, Pardo F, Angelini V, Fazio S \& Sacca L. Impact of hyperthyroidism and its correction on vascular reactivity in humans. Circulation 2001 104 3076-3080.

42 Kahaly GJ \& Dillmann WH. Thyroid hormone action in the heart. Endocrine Reviews 200526 704-728.

43 Biondi B, Palmieri EA, Lombardi G \& Fazio S. Effects of subclinical thyroid dysfunction on the heart. Annals of Internal Medicine 2002 137 904-914.
44 Yönem O, Dokmetas HS, Aslan SM \& Erselcan T. Is antithyroid treatment really relevant for young patients with subclinical hyperthyroidism? Endocrine Journal 200249 307-314.

45 Nurnberger J, Kribben A, Philipp T \& Erbel R. Arterial compliance (stiffness) as a marker of subclinical atherosclerosis. Herz 200732 379-386.

46 Inaba M, Henmi Y, Kumeda Y, Ueda M, Nagata M, Emoto M, Ishikawa T, Ishimura E \& Nishizawa Y. Increased stiffness in common carotid artery in hyperthyroid Graves' disease patients. Biomedicine and Pharmacotherapy 200256 241-246.

47 Czarkowski M, Hilgertner L, Powalowski T \& Radomski D. The stiffness of the common carotid artery in patients with Graves' disease. International Angiology 200221 152-157.

48 Fassbender WJ, Schluter S, Stracke H, Bretzel RG, Waas W \& Tillmanns H. Thyroid function after iodine-containing contrast agent administration in coronary angiography: a prospective study of euthyroid patients. Zeitschrift fur Kardiologie 200190 751-759.

Received 11 May 2008

Accepted 18 May 2008 